\title{
FORMAÇÃO DE CONCEITOS CIENTÍFICOS USANDO O TEMA DOS VEGETAIS COM ESTUDANTES DO ENSINO FUNDAMENTAL
}

\author{
SCIENTIFIC CONCEPTS FORMATION ABOUT VEGETABLES WITH \\ ELEMENTARY STUDENTS
}

Lindalva Sâmela Jacaúna de Oliveira ${ }^{1}$

ORCID iD: 0000-0001-6667-5164

Ana Paula Melo Fonseca ${ }^{2}$

ORCID iD: 0000-0003-3189-3924

Augusto Fachín Terán ${ }^{3}$

ORCID iD: $\underline{0000-0001-9568-7578}$

\begin{abstract}
RESUMO
É importante entender que o processo de formação de conceitos científicos é extremamente relevante para o desenvolvimento cognitivo dos estudantes, uma vez que os conhecimentos existentes em sua estrutura cognitiva será a base para novos conceitos. Este trabalho tem como objetivo compreender como os conceitos espontâneos contribuem para a formação de conceitos científicos usando o tema dos vegetais. A pesquisa é do tipo qualitativo. Utilizamos as técnicas de observação participante e roda de conversa. Foram registradas as falas e as ações dos estudantes. A pesquisa realizou-se em uma escola ribeirinha no município de Parintins-AM, com estudantes do $4^{\circ}$ ano do Ensino Fundamental. Os resultados obtidos evidenciaram que os conceitos espontâneos dos estudantes contribuíram para a compreensão dos conceitos científicos apresentados na roda de conversa. Além dos avanços conceituais, este trabalho reflete sobre o uso de estratégias didáticas que podem incentivar os alunos a pensar e analisar o mundo em que vivem, a fim de entender os problemas em seu cotidiano.
\end{abstract}

Palavras-chave: Ensino de Ciências. Conceito Espontâneo. Conceito Científico.

\begin{abstract}
Understanding the process of scientific concept formation is of paramount importance to the cognitive development of the student, since the existing knowledge in their cognitive structure will be the basis for structuring the concepts in the mind. The aim of this paper is to understand how spontaneous concepts contribute to the formation of scientific concept using the theme of vegetables. The research is qualitative. The technique used was participant observation and conversation wheel. The speech and
\end{abstract}

${ }^{1}$ Graduada em Pedagogia, Mestranda do Programa de Pós-Graduação em Educação em Ensino de Ciências na Amazônia da Universidade do Estado do Amazonas (UEA), Manaus, Amazonas, Brasil. Endereço para correspondência: Rua: Otávio Cabral, casa 27, Petrópolis, Manaus, Amazonas, Brasil, CEP: 69067-370. E-mail: lindalva1802@gmail.com.

${ }^{2}$ Graduada em Pedagogia, Mestre em Educação e Ensino de Ciências na Amazônia pela Universidade do Estado do Amazonas (UEA). Parintins, Amazonas, Brasil. Endereço para correspondência: Rua/Av. Estrada do Macurany, casa 1748, bairro Jacarecanga, Parintins, Amazonas, Brasil, CEP: 69152-240. E-mail: anafonseca23@outlook.com.

${ }_{3}^{3}$ Doutor em Ecologia. Instituto Nacional de Pesquisas da Amazônia (INPA). Professor do Curso de Pedagogia e do Programa de Pós-Graduação em Educação e Ensino de Ciências na Amazônia da Universidade do Estado do Amazonas (UEA), Manaus,Amazonas, Brasil. Endereço para correspondência: Rua Silvania, casa 89, Conjunto Villar Câmara, bairro Aleixo, Manaus, Amazonas, Brasil, CEP: 69083-410. E-mail: fachinteran@ yahoo.com.br.

Revista REAMEC, Cuiabá (MT), v. 8, n. 1, p. 43-54, janeiro-abril, 2020. 
actions of the students were recorded. The research was conducted at a riverside school in the city of Parintins-AM, with students of the 4th year of elementary school. The results showed that the students' spontaneous concepts contributed to the understanding of the scientific concepts presented in the conversation wheel. In addition to the conceptual advances, the work reflects the use of didactic strategies that encourage students to think and analyze the world in which they live, in order to understand the problems present in their daily lives.

Keywords: Science Teaching. Spontaneous Concept. Scientific Concept.

\section{INTRODUÇÃO}

A floresta Amazônica possui uma grande diversidade de recursos florísticos, sendo o lócus ideal para pesquisas relacionadas ao ensino dos vegetais, bem como de outros temas relacionados ao contexto amazônico. Diante da presença de diversas espécies vegetais em volta das escolas ribeirinhas, compreende-se a importância da utilização deste recurso nas aulas de ciências, sendo possível ir além das fotos e figuras existentes no livro didático.

O tema dos vegetais pode ser trabalhado de diferentes maneiras na sala de aula ou fora dela, desde que se tenham objetivos claros e se conduza ao estudante à reflexão, indagação e discussão. Entretanto, saber utilizar e enxergar os recursos disponíveis na natureza ainda é um obstáculo a ser superado pela maioria dos educadores, em especial os das áreas ribeirinhas do baixo Amazonas.

O estudo em questão busca compreender os aspectos que contribuem para a formação de conceito científico a partir dos conceitos espontâneos, sendo estes adquiridos por meio das interações sociais e culturais na comunidade, buscando investigar em que momento esses conceitos afloram para se complementar aos conceitos científicos trabalhados em sala de aula. Em função disto, o objetivo deste trabalho foi compreender como os conceitos espontâneos contribuem para a formação de conceito científico usando o tema dos vegetais com estudantes do $4^{\mathrm{o}}$ ano do Ensino Fundamental em uma escola ribeirinha Amazônica.

\section{REFERENCIAIS TEÓRICOS}

\subsection{Formação de conceito científico no ensino de Ciências}

Para Galvão et al. (2011) os conceitos científicos no ensino de Ciências são fundamentais na vida do ser humano, pois compreendemos com eles os "fenômenos naturais" como também facilitam a leitura de mundo. Azevedo (2008) afirma que apenas "transmitir 
conceitos não logra resultados satisfatórios quanto aos objetivos escolares", nesse sentido é necessário que o educador transcenda ao ensino bancário e utilize de outros caminhos para a construção do conhecimento científico.

Os saberes prévios dos estudantes quando mediados pelo educador são a base para a formação dos conceitos científicos. Galvão et al. (2011, p. 144) dizem que esses conceitos:

\footnotetext{
Libertam o pensamento, a aprendizagem e a comunicação do mundo físico, tornando possível a aquisição de ideias abstratas que servirão para categorizar situações novas e facilitar a assimilação e descoberta de novos conhecimentos. Esse entendimento perpassa os limites de que vivemos num mundo conceitual, e que a realidade que vivemos está relacionada indiretamente às propriedades físicas de nosso meio e aos nossos sentidos sensoriais.
}

Para Sforni (2004, p. 48) os conceitos “[...] ampliam o horizonte da percepção e modificam as formas de interação com a realidade [...]" e de acordo com Vigotski (2005, p. 115), “os conceitos científicos, com o seu sistema hierárquico de inter-relações, parecem constituir o meio na qual a consciência e o domínio se desenvolvem [...]”. Compreende-se então que a formação dos conceitos científicos é essencial para o desenvolvimento da aprendizagem do indivíduo e sua tomada de consciência da realidade, tornando-o apto a solucionar problemas e ao enfrentamento das questões sejam elas sociais, econômicas, políticas e ambientais.

Nesse sentido, vislumbra-se na sala aula, possibilidades de desenvolver práxis pedagógicas diferenciadas, com intencionalidade e organizadas sistematicamente no ensino de Ciências, conectando o indivíduo à realidade, fazendo-o refletir sobre as problemáticas que vivencia diariamente, favorecendo deste modo a formação dos conceitos científicos.

\subsection{Saberes e conceitos cotidianos e a formação dos conceitos científicos}

Para o ser humano se desenvolver, é necessário relacionar-se com outros indivíduos, esta interação o faz adquirir conhecimentos e experiências vivenciadas em seu cotidiano. Por isso, a valorização desses conhecimentos amplia as possibilidades de conhecer o universo a sua volta.

Segundo Lima (2018, p. 43) “o processo de formação de conceitos científicos dependerá da atividade em que o estudante está inserido, por isso, a educação escolar é primordial na mediação entre os conceitos cotidianos". É nesse espaço que a criança tem os primeiros contatos com os conhecimentos cientificamente elaborados, sendo necessária uma apresentação favorável e eficiente para a construção e ressignificação do conhecimento. 
A influência dos saberes cotidianos na formação dos conceitos científicos é identificada em sala de aula quando há contextualização com a realidade vivenciada pelo estudante. De acordo com Galvão et al. (2011, p. 143):

[...] para que a criança tenha um bom desenvolvimento na formação de conceito científico é necessário que, ela tenha em seus conceitos cotidianos, mediados pela atividade de interação coletiva com o mundo e com as pessoas, alcançando certo nível de desenvolvimento para que possa absorver um conceito correlatado. Isso tudo implica na compreensão de que o entendimento da criança sobre determinados conceitos é determinado por seus encontros com o mundo físico, com as interações exercidas com outros sujeitos e com suas experiências vivenciadas em seu contexto sociocultural, aspectos esses que contribuem com o significado e com o sentido de humanização do homem.

Deste modo, a interação com o mundo deve ser propiciada na escola, pois é o espaço de ensino e aprendizagem. O conhecimento está em constante transformação, pois o ser humano vive em contínuo processo de aprendizado. É possível a partir disso, influenciar diretamente no modo de como o ser humano se relaciona com o mundo a sua volta e se identifica como sujeito construtor de sua própria história (SCHROEDER, 2007).

Vygotsky (2005) estudou o processo de desenvolvimento do ser humano, classificando em dois tipos: conceitos espontâneos, desenvolvidos a partir das interações sociais e culturais, enquanto os conceitos científicos são adquiridos por meio do ensino, em situações formais e sistematizados, ocorrendo em sala de aula ou em espaços educativos não formais.

A respeito dos conceitos espontâneos e científicos, este mesmo teórico aponta que:

A criança adquire consciência dos seus conceitos espontâneos relativamente tarde; a capacidade de defini-los por meio de palavras, de operar com eles a vontade, aparece muito depois de ter adquirido os conceitos. Ela possui o conceito (...), mas não está consciente do seu ato de pensamento. O desenvolvimento de um conceito científico, por outro lado, geralmente começa com sua definição verbal e com sua aplicação em operações não-espontâneas (...) poder-se-ia a dizer que o desenvolvimento dos conceitos da criança é ascendente (indutivo), enquanto o desenvolvimento de seus conceitos científicos é descendente (dedutivo) (VYGOTSKY, 2005, p. 93).

Os conceitos espontâneos e científicos devem ser trabalhados juntos, pois se complementam como elos que contribuem para a aprendizagem dos estudantes. É necessário enfatizar que a introdução de conceitos científicos não significa uma compreensão integral, pois é essencial a contextualização com o cotidiano do estudante, contribuindo para o aprimoramento dos conceitos científicos.

Em sala de aula é possível contemplar um ensino diversificado e significativo, pois a valorização desses conhecimentos é de extrema relevância para os estudantes, já que é possível 
a partir disso estimular de forma efetiva o seu desenvolvimento. Uma aula de Ciências que valoriza os conhecimentos oriundos de suas experiências é muito mais rica, sendo capaz de superar as dificuldades do ensino em vários aspectos como a falta de Laboratório de Ciências.

O desafio de desenvolver práticas que subsidiem a formação de conceitos científicos ainda é um grande desafio para maioria dos professores de escolas ribeirinhas. Mortimer (2000, p. 36) salienta que "as ideias prévias dos estudantes desempenham um papel fundamental no processo de aprendizagem". Por isso, o professor tem a necessidade de realizar uma articulação entre os saberes cotidianos dos estudantes com o saber escolar, difundindo um ensino que possibilite o acesso à ciência de forma inovadora desenvolvendo as capacidades cognitivas dos estudantes.

\section{MATERIAIS E MÉTODOS}

A pesquisa foi realizada em uma escola ribeirinha da comunidade do Parananema, pertencente à área Peri urbana do município de Parintins-AM, localizada a 9 km do centro da cidade. Os sujeitos da pesquisa foram 17 crianças do $4^{\circ}$ ano do Ensino Fundamental e um docente. A comunidade possui belezas naturais e é circundada pelo lago do Macurany (SILVA, 2012), onde é possível o uso dos vegetais nas aulas do componente curricular Ciências.

Esta pesquisa tem abordagem qualitativa, pois, favorece uma relação recíproca entre pesquisador e o contexto pesquisado, contribuindo para o desenvolvimento do conhecimento científico (TRIVIÑOS, 2015). A abordagem é fenomenológica, possibilitando a compreensão do fenômeno pesquisado a partir de sua própria realidade, e como vêem o mundo a partir de suas experiências (GIL, 2010).

A técnica de pesquisa foi a observação participante, diário de campo e a roda de conversa. Para Moura e Lima (2014, p. 99) a roda de conversa "é no âmbito da pesquisa narrativa, uma forma de produzir dados em que o pesquisador se insere como sujeito da pesquisa pela participação na conversa e, ao mesmo tempo, produz dados para discussão". A partir disto foi possível descrever as ações dos estudantes, assim como participar das atividades escolares. 


\section{RESULTADOS E DISCUSSÃO}

\subsection{Roda de conversa e a formação de conceitos científicos sobre os vegetais}

O processo de formação de conceito científico é bastante complexo e necessário para a construção do conhecimento científico do ser humano. Na educação em ciência é constituído como elemento central desta área de estudo (LIMA, 2011). Por meio de estratégias diferenciadas, é possível instigar os estudantes a conhecer o mundo em que vivem e os fenômenos naturais, por tanto, compreender como se desenvolve e quais elementos são necessários para sua formação contribuem para articulação de estratégias didáticas em sala de aula.

De acordo com Moura e Lima (2014, p. 99) uma das estratégias possíveis de serem utilizadas em sala de aula é a roda de conversa, pois, por meio delas é possível desenvolver diálogos significativos.

[...] o diálogo é um momento singular de partilha, porque pressupõe um exercício de escuta e de fala, em que se agregam vários interlocutores, e os momentos de escuta são mais numerosos do que os de fala. As colocações de cada participante são construídas por meio da interação com o outro, seja para complementar, discordar, seja para concordar com a fala imediatamente anterior.

Diante disso, para trabalhar conceitos científicos presentes no tema dos vegetais, utilizou-se a roda de conversa para articular com os conceitos espontâneos por meio de diálogo, estabelecendo um momento de partilha dos conhecimentos, deixando-os seguros para se expressarem a respeito do conteúdo trabalhado.

Segundo Maciel e Fachín-Terán (2013, p. 249) “[...] uma aula expositiva dialogada requer do aluno uma participação ativa em que ele consiga estabelecer uma relação entre o conteúdo novo e o já existente na sua estrutura cognitiva". Essa exposição do tema dos vegetais tornou-se um momento de muito aprendizado, sendo valorizadas as ações, vivências e experiências do seu cotidiano, onde são adquiridos os conceitos espontâneos.

Por isso, a roda de conversa foi estabelecida a priori com uma conversa informal para observar a relação das crianças com os vegetais, pelo fato de residirem em uma comunidade ribeirinha, onde o contato com a natureza está presente em atividades como: pescar, brincar ao ar livre, tomar banho no rio, dentre outras atividades presentes em sua vida cotidiana.

Para motivar os estudantes, realizou-se a dinâmica de escolha de nomes fictícios de plantas conhecidas a partir de suas vivências, e assim foi iniciada a introdução do tema dos 
vegetais de maneira sucinta, onde puderam escolher de maneira livre seus nomes. Durante este processo os estudantes dialogaram entre si e registrou-se expressões como: "Eu nunca tive nome de planta, vou escolher o nome de uma flor, sabe por que, professora? É porque eu acho que combina mais com meninas" (Flor do meio dia, criança de 10 anos).

Gonzaga (2013, p. 51) destaca que "o homem, na busca de compreensão de sua condição humana, tende a criar alternativas para ensinar e aprender com os outros", assim as crianças buscaram nesse momento, aprender uma com as outras a escolher o seu nome, sendo fundamental essa interação para aprender sobre os vegetais e sua relação com o homem.

Após a escolha dos nomes, momento de interação entre eles, buscou-se alternativas para começar a instigá-los a refletir sobre sua realidade, como por exemplo, evidenciou-se o entorno da escola, a comunidade, o caminho de ida e vinda para a escola, sendo possível registrar o conhecimento dos estudantes sobre os vegetais a partir de seu cotidiano (Quadro 1).

\begin{tabular}{|l|c|l|}
\hline $\begin{array}{l}\text { Nome fictício } \\
\text { assumido pelos } \\
\text { estudantes }\end{array}$ & Idade & Falas das crianças sobre os vegetais de sua comunidade \\
\hline Castanheira & 09 & $\begin{array}{l}\text { "As arvores da comunidade estão ficando poucas, porque estão cortando demais, } \\
\text { e isso aumenta o calor, sabia professora? ". }\end{array}$ \\
\hline Rosa & 10 & $\begin{array}{l}\text { "As plantas da escola são legais e temos que cuidar, mas só que as arvores que } \\
\text { fica no caminho de casa são melhor, porque dão sombra pra nós". }\end{array}$ \\
\hline Pinheiro & 10 & $\begin{array}{l}\text { "Ao redor da escola tem as plantas, essas plantas professora foram plantadas } \\
\text { pra enfeitar a escola, a senhora já viu uma escola sem planta? Não é legal né? } \\
\text { Eu também acho que devemos cuidar das plantinhas aqui da escola". }\end{array}$ \\
\hline
\end{tabular}

Quadro 1: Registro das falas das crianças sobre os vegetais.

Fonte: Diário de Campo, 2015.

Para introduzir novos conceitos é necessário direcionar o olhar pedagógico para a realidade na qual o estudante está inserido. Pelas observações percebeu-se que a maioria tinha percepção ambiental relacionado ao clima e ao calor excessivo devido ao desmatamento na comunidade.

Em função disto, é necessário fazer a ligação do conhecimento científico com os problemas que atingem o cotidiano, sendo possível refletir as ações do homem sobre o meio ambiente, construindo a partir disso, novos conceitos sobre os vegetais em relação ao contexto amazônico na qual estão inseridos. Destacamos o pensamento de Raven (2013, p.1) que diz: "[...] somos totalmente dependentes das plantas" é por meio delas que hoje a ciência tem evoluído bastante no que diz respeito à busca de uma melhor qualidade de vida.

Diante da abordagem realizada para verificar a relação dos estudantes com os vegetais, usou-se como instrumento de ensino um pequeno galho de uma arvore para representar de 
maneira concreta um vegetal, onde puderam perceber e visualizarem suas características e foi explicada os conceitos e funções para a planta sobreviver. Seguidamente foi perguntado aos estudantes, vocês sabem o que é um vegetal? Onde eles expressaram o que entendiam sobre os vegetais.

Nesse momento, não foi dado inferência a nenhum espaço da comunidade, com o intuito que eles refletissem sobre o que tinha sido perguntado, sendo possível identificar os conceitos espontâneos. No quadro 2 destacam-se algumas das falas e concepções em relação aos vegetais.

\begin{tabular}{|l|c|l|}
\hline $\begin{array}{l}\text { Nome fictício assumido } \\
\text { pelos estudantes }\end{array}$ & Idade & $\begin{array}{c}\text { Pergunta motivadora: } \\
\text { Vocês sabem o que é um vegetal? }\end{array}$ \\
\hline Vitória-Régia & 09 & "Bom, eu acho que é são as plantas". \\
\hline Cupuaçu & 10 & "Eu sei, professora, são as todas as plantinhas que existem no mundo". \\
\hline Castanheira & 10 & $\begin{array}{l}\text { "Os vegetais são também seres vivos, são as plantas e arvores, elas são } \\
\text { importante, lá em casa a mamãe faz até chá, quando estou com dor de } \\
\text { estômago". }\end{array}$ \\
\hline Hortelã & 10 & $\begin{array}{l}\text { "São as plantas, até aquelas plantinhas bem pequeninas que tem no } \\
\text { mundo, ne professora? }\end{array}$ \\
\hline & Quadro 2: Falas dos estudantes relacionadas aos vegetais. \\
Fonte: Diário de Campo, 2015.
\end{tabular}

As falas das crianças evidenciam a presença constante de suas vivências cotidianas. Destacam-se no quadro 2, que algumas crianças conseguiram responder de forma espontânea o que caracteriza um vegetal, outras demonstram saber termos científicos e também a importância dos vegetais para os seres humanos.

Esse momento de compartilhamento de conhecimento favoreceu a aprendizagem dos demais estudantes que não conseguiram responder do que se trata um vegetal, pois, apesar de viverem em um espaço rico em espécies de plantas, uma parcela pequena dos estudantes não conhecia o termo vegetal e não verbalizaram o que havia sido perguntado.

O trabalho desenvolvido mostra o quanto há necessidade de estimular os estudantes a falar, ouvir e questionar, pois "o processo de formação de conceitos científicos envolve a apropriação, pelos estudantes, dos novos modos de falar e pensar o mundo" (LIMA, 2011, p. 858).

Destacamos, que o contexto amazônico na qual as crianças vivem contribui de maneira significativa para o aprendizado dos conceitos científicos. Para Araújo e Fachín-Terán (2013), a floresta amazônica é um laboratório vivo para o ensino de ciências, tornando-se assim um instrumento essencial para a formação de conceitos científicos.

A abordagem sobre o tema dos vegetais iniciou-se sobre as partes da planta a partir dos seguintes conceitos: raiz, caule, folha, fruto e o processo de fotossíntese. Na roda de conversa 
houve várias perguntas a respeito dos vegetais relacionadas ao cotidiano, onde pode-se perceber uma relação afetiva dos estudantes com as arvores (Quadro 3).

\begin{tabular}{|l|c|l|}
\hline $\begin{array}{l}\text { Nome fictício } \\
\text { assumido pelos } \\
\text { estudantes }\end{array}$ & Idade & $\begin{array}{l}\text { Pergunta motivadora: } \\
\text { Na casa de vocês existe alguma arvore? }\end{array}$ \\
\hline Babosa & 09 & $\begin{array}{l}\text { "Professora, antes lá em casa tinha um jambeiro, mas o papai cortou e ficamos } \\
\text { sem arvore grande no quintal de casa, mas ao redor têm váriasarvores, no } \\
\text { caminho que tenho que ir pra escola e voltar pra casa, elas têm bastantes folhas } \\
\text { e algumas são grandes, o bom que da sombra". }\end{array}$ \\
\hline Pau-Brasil & 09 & $\begin{array}{l}\text { "La em casa tem professora, eu sei quais são as partes da planta, é raiz, caule, } \\
\text { folha, fruto e flor". }\end{array}$ \\
\hline Piquiazeiro & 10 & $\begin{array}{l}\text { "Em casa tem várias, algumas dão frutos e outras à mamãe planta porque serve } \\
\text { pra remédio mesmo". }\end{array}$ \\
\hline
\end{tabular}

Quadro 3: Falas dos estudantes sobre a presença de arvores em seu cotidiano.

Fonte: Diário de Campo, 2015.

Nas falas dos estudantes, foram destacadas as características e funções de cada parte da planta como: folhas responsáveis pela transpiração, respiração e alimentação das plantas; flores: responsáveis pela formação do fruto e da semente; caule: responsável pela sustentação da planta e por levar água e sais minerais da raiz para as outras partes dela. Assim como os seres humanos precisam de alimentos, as plantas também, necessitam de nutrientes para viver. E, esse processo se chama de fotossíntese (RAVEN, 2013).

Segundo Gonzaga (2013, p. 44) “[...] deve existir um elo entre o que o indivíduo já sabe, e o que ele deve saber, para que, efetivamente, possa ocorrer a aprendizagem significativa. É o que nos atreveríamos a chamar de "link", ou "pontes cognitivas". E, esse elo é perceptível quando se valorizam os conhecimentos prévios dos estudantes, dando abertura para a construção de novos conhecimentos. Em função de isso, durante a roda de conversa foi dado a inferência aos conhecimentos espontâneos dos estudantes, fazendo uma relação com o conhecimento científico, onde foi estabelecido um novo conhecimento e aprimorando o seu saber primeiro sobre os vegetais e suas respectivas espécies. Na roda de conversa os estudantes refletiram cada conceito apresentado, os pesquisadores estimulavam e os questionavam sobre o que era apresentados aos estudantes.

Para Vygotsky (2005) os seres humanos possuem a capacidade de construir conhecimento por meio de ações, portanto, o uso dos conceitos espontâneos e das concepções dos estudantes é essencial para a formação dos conceitos científicos, tal como podemos observar nas expressões registradas na roda de conversa realizada com os estudantes sobre o assunto das raízes (Quadro 4). 


\begin{tabular}{|l|l|l|}
\hline $\begin{array}{l}\text { Nome fictício } \\
\text { assumido pelos } \\
\text { estudantes }\end{array}$ & Idade & $\begin{array}{l}\text { Pergunta motivadora: } \\
\text { Vocês sabem qual é a função da raiz da planta? }\end{array}$ \\
\hline Mangueira & 09 & $\begin{array}{l}\text { "Um dia eu quero estudar sobre essas plantas, professora, eu gostei de } \\
\text { observar, não sabia que esses negocinhos durinhos que tem na folha se } \\
\text { chama nervura, é tipo nossa veia de sangue mesmo, estou vendo aqui, é muito } \\
\text { legal isso". }\end{array}$ \\
\hline Flor do meio dia & 10 & $\begin{array}{l}\text { "Professora, eu sei pra que serve a raiz, serve pra nós sentar embaixo da } \\
\text { árvore, quando está sombra, e também para segurar a árvore ou planta se } \\
\text { não ela não fica em pé". } \\
\text { "Eu nunca observei os caules das plantas que a escola tem e também os de } \\
\text { casa, e não encontrei diferenças, por isso, professora, que pra mim são todos } \\
\text { iguais". }\end{array}$ \\
\hline Pinheiro & 10 & $\begin{array}{l}\text { Quadro } \\
\text { Qún }\end{array}$ \\
\hline
\end{tabular}

Quadro 4: Falas dos estudantes sobre as raízes.

Fonte: Diário de Campo, 2015.

Diante da realidade trabalhada na roda de conversa, detectamos que os conhecimentos adquiridos despertam a curiosidade das crianças, pois a partir disso é possível destacar o que passou despercebido, o que não conseguiam compreender no início da aula. A técnica da roda de conversa possibilitou a compreensão dos vegetais de maneira significativa, pois os instrumentos trazidos contribuíram para se obter uma nova concepção sobre os vegetais, sua importância para a vida na terra, além da construção dos conceitos científicos.

A partir dos conceitos espontâneos, a respeito dos vegetais, percebeu-se que a maioria dos estudantes compreendeu as funções dos vegetais de forma simples e contextualizada, por exemplo: para um dos estudantes uma das funções das raízes da planta era para senta-se e conversar. A partir da dinâmica da roda de conversa foi possível estabelecer uma evolução conceitual do conceito de raiz, fazendo-os compreender que além dessa função da raiz (que não deixa de ser certa, pois é a percepção do estudante), existe a verdadeira função da raiz para a planta.

Pelizzari et al. (2002, p.38) enfatiza que "a aprendizagem é muito mais significativa à medida que o novo conteúdo é incorporado às estruturas de conhecimento de um aluno e adquire significado para ele a partir da relação com seu conhecimento prévio". Contudo, o ensino de Ciências necessita de novas metodologias que vislumbrem um ensino capaz de formar seres humanos críticos e capazes de questionar e discutir sobre as problemáticas cotidianas.

\section{CONSIDERAÇÕES}

O uso dos conceitos espontâneos oriundos das vivências sociais dos estudantes demonstra sua contribuição para assimilação dos conceitos científicos apresentados em sala de 
aula. O processo de ressignificação do conhecimento parte do pressuposto que é necessária a valorização destes conhecimentos primeiros, a fim de chegar ao conhecimento científico.

O processo de formação de conceito científico é um processo complexo que demanda tempo e maturação na mente do ser humano. Diante disso, há a necessidade de estabelecer metodologias de trabalho capazes de estimular o aprendizado conceitual dos estudantes. Foi perceptível o quanto as crianças demonstraram interesse em conhecer os vegetais, visto estar presente no seu cotidiano, mas não possuíam o olhar do que a ciência propõe, um olhar com curiosidade, reflexivo e crítico de sua realidade.

$\mathrm{O}$ contexto amazônico no qual as crianças vivem contribui para o aprendizado dos conceitos científicos e a roda de conversa possibilitou a introdução desses conceitos, tendo como destaque os conceitos espontâneos dos estudantes, a fim de desenvolver o entendimento sobre os vegetais a partir de suas experiências de sala de aula e também do convívio social. Os conceitos espontâneos contribuíram de maneira significativa para o processo de formação dos conceitos científicos, pois percebeu-se uma evolução conceitual a partir do que já possuíam em relação ao tema dos vegetais.

\section{REFERÊNCIAS}

ARAÚJO. J. N; SILVA, C. C; FACHÍN-TERÁN, A. A floresta Amazônica: Um espaço não formal em potencial para o ensino de ciências. In: FACHÍN-TERÁN, A; SANTOS, S. C. S. Novas perspectivas de ensino de ciências em espaços não formais amazônicos. Manaus: UEA edições, 2011.

AZEVEDO, R. O. M. Ensino de Ciências e formação de professores: diagnóstico, análise e proposta. Programa de Pós-Graduação em Educação e Ensino Ciências na Amazônia. (Dissertação de mestrado) Universidade do Estado do Amazonas, Manaus: UEA, 2008.

GALVÃO. M. L.; LIZARDI, P.; FACHÍN-TERÁN, A. Os processos cognitivos da criança, a formação de conceitos e ensino de ciências. In: BARBOSA, I; FACHÍN-TERÁN, A.; GONZAGA, A. M.; SANTOS, S. C. S. Educação em ciências na Amazônia: Múltiplos olhares. Manaus: UEA edições. Escola Normal Superior/PPGEECA, 2011.

GIL, A. C. Como elaborar projetos de pesquisa. 5 ed. São Paulo: Atlas, 2010.

GONZAGA, A. M. Reflexões sobre o ensino de Ciências. Curitiba, PR: CRV, 2013.

LIMA, A. C. S. Uma reflexão acerca da formação de conceitos científicos na disciplina de Ciências Naturais no Ensino Fundamental em uma escola pública de Manaus. Programa de Pós-Graduação em Educação e Ensino Ciências na Amazônia. (Dissertação de mestrado) Universidade do Estado do Amazonas, Manaus: UEA, 2018. 
MACIEL, H. M.; FACHÍN-TERÁN, A. Possibilidades de Alfabetização Ecológica usando o tema cadeia alimentar no $6^{\circ}$ ano do Ensino Fundamental. In: FACHÍN-TERÁN, A.; SANTOS, S. C. S. Novas perspectivas de ensino de ciências em espaços não formais amazônicos. Manaus: UEA Edições, 2013.

MOURA, A. F.; LIMA, M. G.A reinvenção da roda: roda de conversa: um instrumento metodológico possível. In: Revista Temas em Educação, João Pessoa, v.23, n.1, p. 98-106, jan.-jun. 2014.

MORTIMER, E. F. Linguagem e formação de conceitos no ensino de Ciências. Belo Horizonte: Ed. UFMG, 2000.

PELIZZARI, A.; KRIEGL, M. L.; BARON, M. P.; FINCK, N. T. L.; DOROCINSKI, S. I. Teoria da Aprendizagem Significativa segundo Ausubel. Rev. PEC, Curitiba, v.2, n.1, Julho. 2001/Julho 2002.

RAVEN, P. H.; EVERT, R. F.; EICHHORN, S. E. Biologia Vegetal. [coordenação de tradução Jane Elizabeth Kraus; revisão técnica Jane Elizabeth Kraus, Neuza Maria de Castro, tradução Ana Cláudia de Mâcedo Vieira et al.] [Reimpr]. Rio de Janeiro: Guanabara Koogan, 2013.

SFORNI, M. S. F. Aprendizagem conceitual e organização do ensino: contribuições da Teoria da Atividade. Araraquara: JM Editora, 2004.

SCHROEDER, E. Conceitos espontâneos e conceito científicos: O processo da construção conceitual em Vygotsky. Rev. Atos de Pesquisa em Educação, v.2, n.2. Maio/Agosto 2007.

SILVA, D. X. Educação científica a partir de atividade de conservação de quelônios Amazônicos em Comunidade ribeirinhas do Baixo Amazonas. (Dissertação de Mestrado). Universidade do Estado do Amazonas. Manaus: UEA, 2012.

TRIVIÑOS, A. N. S. Introdução à pesquisa em ciências sociais: a pesquisa qualitativa em educação. 23 Reimp. São Paulo: Atlas, 2015.

VYGOTSKY, L. S. Pensamento e linguagem. 3 ed. São Paulo: Martins Fontes, 2005.

Submetido em: 09 de agosto de 2019. Aprovado em: 20 de dezembro de 2019. 